\title{
Levels of Conformity to Leader in Normal and Critical Situations
}

\author{
Yüksel Gündüz \\ College of Education, Ondokuz Mayis University, Turkey
}

Copyright $\subset 2017$ by authors, all rights reserved. Authors agree that this article remains permanently open access under the terms of the Creative Commons Attribution License 4.0 International License

\begin{abstract}
The aim of this study is to determine primary school, middle school, high school and university students' levels of conformity to leader in normal and critical situations. Experimental model was used in the research. Study group is comprised of 80 students chosen randomly from Karadeniz Bakır Primary School, Gazi Middle School, Kazım Karabekir Anatolian High School and the department of Primary Education, Faculty of Education, Artvin Çoruh University, Turkey in 2015-2016 academic year. Participants' levels of conformity to leader in normal and critical situations were determined by first calculating group averages in normal and critical conditions to see its proximity from leader's estimate, then differences between leaders' estimates and participants' estimates were calculated to determine participants' levels of conformity to leader in each group, and finally averages of the differences in four separate conditions (NC-w/o leader, $\mathrm{NC}$-w/leader, $\mathrm{CC}-\mathrm{w} / \mathrm{o}$ leader, CC-w/leader) were calculated. Results gained in this study reveal that middle school, high school and university students didn't display much conformity behaviour to leader in normal situations, but primary school students displayed higher conformity behaviour to leader. However, primary school, middle school, high school and university students displayed conformity behaviour to leader in high levels in critical situation. While students generally didn't display conformity behaviour to leader whom they chose for both situations in normal situation, they highly displayed conformity in critical situation.
\end{abstract}

Keywords Leader, Conformity to Leader, Normal Situation, Critical Situation, Student

\section{Introduction}

Since people are social beings living in groups, they have always needed leaders who could head groups and make them achieve their goals. Necessity of organisation for people to meet their needs and attaining their objectives entail a leader. Creating people groups directed to specific goals and objectives and activating them requires especial skills which cannot found in every person and ability to persuade. However, this ability does not mean that there is an innate characteristic, because leadership is a set of behaviours that can be learned. In this sense, a leader is a person who can gather a group around certain purposes and has skills and knowledge to influence and mobilise them for these purposes. Since the emergence of the human community, leaders have existed. Though the concept of leadership has had very different meanings in all areas of management from the earliest times to present, it has always existed and hasn't lost its significance. In general, if individuals are impressed by a person to achieve goals, there is leadership. As leadership is a versatile and rich concept expressed with different meanings by different people, it is difficult to make a clear and precise definition of leadership. Here, it's useful to lay emphasis on the concept of leader first and then leadership.

There is a wide collection of different definitions of the leader. Seen in this light, for example, leader, as a member of the group, is a person who has a positive effect on other members [1]. In this sense, leader is described as a person having power to influence people towards attaining common goals. On the other hand, leader is also defined as someone who evaluates and regulates the group's experiences and takes advantage of the power of the group through these experiences [2]. Leaders motivate people to behave in the desired form, to want to move in that direction [3]. Therefore, leaders must also have leadership competence, managerial skills, cognitive competencies and skills in developing behaviour as occasion requires [4]. It's known that leaders are aware of their own behaviours, traits and skills and they know themselves, their organizations, groups and relations between them well [5]. Despite this, a common personality trait of the leaders has not been defined so far [6]. However, contemporary leadership theorists have focused on contingency. Accordingly, leaders are not limited to the process. On the contrary, they defy to the processes for creative actions [7]. The belief that a complex and irregular organization will be more creative lies behind it. 
On another level, leader is the subject of leadership concept. It's also known that leaders are the ones who understand organisational needs and know management structures well [8]. It is possible to sort certain general characteristics of leaders as considering followers' emotions carefully [9], motivating, developing vision [10], being effective in communication [11], having cognitive behaviours [12], observing the surroundings, being focused on positive thinking [13], taking people's values into account [14], and showing the effect of management feelings [15]. In addition, as a person who reduces uncertainties about mandatory expectations and removes the barriers [16], a leader plays a behaviour supporting role. In this sense, a leader pays attention to followers, approaches friendly, is accessible and creates a supportive working environment [17]. This increases social satisfaction and self-confidence among followers and causes a decrease in fear and stress [18]. Besides all these features, the leader can't make his/her presence felt and can't accomplish his/her goal without followers. Here, the fact that leader can display leadership behaviour depends on a suitable environment and availability of sufficient followers. In this sense, leadership consists of components as leader, followers and environment.

From a broader perspective, a complete consensus seems not to have been reached in the definition of leadership. It's because there is a complex structure like leader, followers and conditions in leadership [10]. Leadership is a social process affecting the interpretation of internal and external events, selection of purpose, arrangement of activities of group members, individual motivation and skills, power relations and common aspects [19]. Some have identified leadership as process of affecting others to make them do what you want. It's known that organizational context is of prime importance on leadership [20]. According to De Vries, Roe and Taillien (2002), the concept of the need for leadership is contextual and context is about to what extent the person evaluates that context safe and unsafe [21]. Leadership might lose its meaning in an environment where there is no one following. Therefore, leadership is a quality that is imparted to person by the group.

As social beings, humans have always required leaders who would manage the groups they formed by coming together temperamentally and carry them through their goals [22]. Therefore, social needs have created leaders [23]. Individuals' assumption that leaders are more knowledgeable and experienced than themselves lies behind creating leaders. This has led individuals to behave more willingly on listening and accepting instructions and recommendations of leaders having more knowledge and experience [24]. The need for leadership is a situation that emerges when human efforts are needed to be combined and coordinated [25]. Personal, organisational and business-related factors affect individuals' need for leadership. The need for leadership is defined as a demand for facilitation of paths to purpose by a leader in line with employees' personal, group and organisational goals. The need for leadership has the characteristics determining to what extent leadership will be regarded as positive and desirable or not [21].

Need is contextual in the sense of individual's being at the discretion of a specific environment. If the environment is such a kind that the person can't show the necessary competencies or will feel insecure, the individual wants leader to help. Conversely, when the individual relies on his/her skills, s/he doesn't want to be interfered by the leader. Leadership becomes more important when individuals need leadership a lot, but it becomes less important when they need it less. In other words, if the need for leadership is high, leadership behaviours are more effective on the individuals; if the need for leadership is low, the effect of it on the individual is also lower. When the need for leadership is low, the guidance of the leader is considered unnecessary and undesirable [21]. This emphasizes that the followers shouldn't be seen as passive entities that follow the leader in all circumstances [26]. However, when individuals' competence falls short for a task, tendency to avoid uncertainty increases. Therefore, their need for leadership will increase. The effect of leadership on the individual will be more. When an individual falls into uncertainty, if s/he can resolve it in any way, the possibility of leaders' intervention to create a positive impact on individual will be very slight [21]. Reducing the role of the leader has a characteristic of increasing the learning capacity of the organisation [27]. However, this can have a speed lowering effect on organisation's decision-making on any issue. In this sense, the leader gives a chance to organisation to make quick decisions and to act fast.

The fact that the individuals' needs for leadership are high means that their needs for autonomy are low. The individual who leaves him/herself to someone's guidance also abandons autonomy and his/her right to decide. As need for autonomy is a term especially closely associated with cultural values, the need for leadership may also be varied according to cultural values $[28,29,30]$. In other words, leadership is a social organisation, so seeing the effects of social and cultural environment in leadership is inevitable [31]. In this sense, cultural values of the individuals are a factor that determines their needs for leadership. Studies have revealed that cultural values of the followers differentiate their needs for leadership. Similar studies have shown that a follower group having certain cultural values preferred a closer management while another group preferred a more flexible leadership style giving them more authority and responsibility [30]. To what extent an individual or community wants their tendency to be coordinated by someone else means the individual or the community gives up their autonomy to the same degree.

Cultural values of individuals are important in determining to what extent they will need leadership or not. For example, Hofstede (1980a), emphasised that cultural 
values affect the individuals' attitudes towards authority and their conformity behaviour [30]. In this sense, the cultural values of the followers determine to what extent individuals will seek the guidance of a leader or prefer autonomy. Depending on cultural values, if the individuals need leadership more, leadership behaviours will be more important and more effective on the results. On the other hand, if individuals' needs for autonomy are greater, their needs for leadership decrease and leadership behaviour becomes less effective on the results. In this sense, the need for leadership will show to what extent the followers will accept the intervention of leaders.

Having collectivistic and individualistic behaviours in individual's cultures also affects the attitudes towards leader and their conformity behaviours. According to Hofstede and Mccree (2004), individualism and collectivism are the essential parts of the culture [32]. While individualism occurs when complexity of the society is high and freedoms expand [33], collectivism occurs in simple and enveloping societies [34]. Collectivistic individuals are inclined to cooperate and social support, but individualists are prone to success and loneliness [35]. While individualistic culture promotes the idea that people are independent, collectivistic culture accepts the idea that people are mutually connected at a high level. While individualistic cultures emphasize to be in the quest of individualism related to self-expression and group goals, collectivistic cultures support continue of social cohesion regarding individualism claim [36, 37, 38]. The basic characteristic that distinguishes collectivistic cultures from individualist cultures is that the person sees him/herself as part of a group but not as an independent individual in collectivistic cultures. As a result, his/her concern is to ensure his/her individual goals and behaviours are in accord with the group norms and expectations [36, 37].

The basic difference between the concepts of and individualism is the difference in self- interpretation [36]. While their own choice and autonomy is important for individualists whose independent self-interpretation is high, the choices made by others for them are more important for collectivists whose dependent self-interpretation is high communitarians [29, 39]. Because the need for others judgment is more significant and the need for autonomy is lower in followers group whose collectivistic values are higher [29, 36], the need for a leader will be more. The need for autonomy and the need for self-management of a follower group which is dominated by individualistic values are higher $[29,36,39,40]$. Thus, followers need for guidance in their work for orientation, will reduce. With the increase in individualist cultural values, followers will assume leader's directive behaviours as a less desirable phenomenon. With the increase in collectivistic cultural values leader's guidance will become a phenomenon needed more for individuals and therefore will gain more importance. As a result, it can be suggested that the effect of the leader on business results might be more in collectivistic values as compared to individualistic values.

\section{Purpose}

The subject of levels of conformity to the leader of primary school, middle school, high school and university students with different socio-economic and cultural structure has become attractive and urged me to do a research. Because in domestic and foreign literature review made by the researchers, such study hasn't been observed. Hence the importance of research stems from here. With this research conducted in this context, primary school, middle school, high school and university students' levels of conformity to leader in normal and critical situations tried to be presented. For this purpose, answers to the following questions were sought.

- What are the primary school, middle school, high school and university students' levels of conformity to leader in normal situation?

- What are the primary school, middle school, high school and university students' levels of conformity to leader in critical situation?

- $\quad$ Are there any differences between the primary school, middle school, high school and university students' levels of conformity to leader in normal and critical situation?

\section{Material and Methods}

In this section, research model, study group, data collection and data analysis techniques in this study are presented.

\subsection{Research Model}

The research was designed as an experimental model because it aims to determine the effect of normal and critical conditions on students' conformity to leader. For this purpose, pre-experimental one group post-test model was used in the research study [41].

\subsection{Study Group}

Study group of the research was determined by using a maximum variation sampling method that is among non-random sampling approaches. In maximum variation sampling method, different situations / groups which study will be implemented in are determined taking into account the aim of the study. Addressing different groups related to problem in this sampling method provides obtaining important clues about values of the universe [42]. In the study, students are selected with maximum variation sampling method from Karadeniz Bakır Primary School, Gazi Middle School, Kazım Karabekir Anatolian High School and Artvin Çoruh University, Education Faculty, 
Department of Primary Education which are in service in the centre of Artvin Province. Area of variety is defined as levels of education in this sampling method. Study group was formed by choosing a school from these levels of education and a class from that school. Studies were carried out in a group of 20 students randomly selected from classes at each specified type of school. The study was done in two stages, the observation of conformity behaviours to leaders in normal and critical situations.

\subsection{Process}

\subsubsection{Normal Situation}

$1^{\text {st }}$ stage. 20 students were randomly selected from $4^{\text {th }}$ grade of primary school, $7^{\text {th }}$ grade of middle school, $10^{\text {th }}$ grade of high school and $4^{\text {th }}$ grade of Primary Education Department.

$2^{\text {nd }}$ stage. The 20 students selected were made to wait in an appropriate place at the school where the study would be carried out and taken into a room one by one where there is an uneven stone weighing $\mathrm{X} \mathrm{kg..} \mathrm{Each} \mathrm{student} \mathrm{inside} \mathrm{was}$ asked the weight of the stone and the value. What they said was recorded by the names of the students. The students whose ideas were received were made to wait at separate places accompanied by teaching assistants and they weren't allowed to communicate with each other. Hence, ideas of all students were recorded. After this process:

$3^{\text {rd }}$ stage. Students whose ideas were recorded (20) were wanted to form 4 groups of 5 for each group and to choose a group leader. After the leaders were chosen:

$4^{\text {th }}$ stage. Teaching assistants charged in receiving ideas without leader were changed in order that students weren't affected. Then first 5 students with a leader were taken into the room with a stone. Leader of the group was asked the weight of stone first and the value was recorded next to the former record on a separate column. After that, leader and the other members of the group were taken out of the room in different directions and were made to wait in separate places in order that group members weren't affected by the leader. Afterwards, other members of the group were called into the room one by one and the weight of the same stone was asked. Their values were recorded to the column next to the former values. These processes were repeated for other groups.

\subsubsection{Critical Situation}

This study was also conducted with the students who participated in the study of conformity to leader in normal situation. Critical situation was created by saying that the group to find the hypercorrect value would be taken to an all expense tour to Georgia-Tbilisi. The same process with normal situation was repeated in critical situation. However, the object (rope instead of stone) used was changed.

$1^{\text {st }}$ stage. Students were taken into the room where there is a "S"-shaped rope $\mathrm{X} \mathrm{m}$. in length one by one. They were asked the length of the rope and their values were recorded by the side of their names. The students whose ideas were received were made to wait at separate places accompanied by teaching assistants and they weren't allowed to communicate with each other. After this process:

$2^{\text {nd }}$ stage. Students were asked to form 4 groups of 5 each and to choose a group leader. After the leader was chosen:

$3^{\text {rd }}$ stage. Teaching assistants charged in receiving ideas without leader were changed so that students would not be affected. Then first group taken into the room with the rope, leader of the group was asked the length of the rope first and the value was recorded next to the former value on a separate column. After that, leaders and the other members of the group were taken out of the room in different directions and were made to wait in separate places in order that group members weren't affected by the leader. Afterwards, other members of the group were called into the room one by one and the length of the rope was asked. Their values were recorded to the column next to the former values. These processes were repeated for other groups. Interactions among students were prevented, for all the stages of the process were under the control of instructors.

\subsection{Data Analysis}

The data collected to determine primary school, middle school, high school and university students' levels of conformity to leader in normal and critical situations were analysed by comparing estimated averages of student groups in each school level with and without leader in normal and critical situations with estimated value of the leader. On the other hand, to determine the levels of conformity to leader of the participants in all levels and groups, differences between leader estimates and participant estimates were calculated, and averages of the differences in four separate conditions (NC-w/o leader, NC-w/leader, $\mathrm{CC}$-w/o leader, CC-w/leader) were calculated. Absolute values of negative differences were calculated to eliminate errors. To calculate levels of conformity to leader (LUD), averages of differences in with leader condition (LDFO) were subtracted from the averages of differences in without leader condition (LzDFO) and then divided by the averages of differences in without leader condition (LzDFO). The procedure is formulated as below.

$$
L U D=\frac{(L z D F O-L D F O)}{L z D F O}
$$

Participants' levels of conformity to leader in normal and critical conditions were calculated with this formula. Hence levels of conformity to leader in normal and critical conditions could be compared. For example: If in the normal condition without leader group average difference is 12.8 , with leader group average difference is 4.3 , and in the critical condition without leader group average difference is 2.0 , with leader group average difference is 0.4 , then students' NC (normal condition) conformity level = $(12.8-4.3) / 12.8=0.67$, and $\mathrm{CC}$ (critical condition) conformity level $=(2.0-0.4) / 2.0=0.81$. Negative values 
indicate a departure from leader's estimate, and positive values indicate approximation to leader's estimate.

\section{Findings}

Findings from the analysis of data gathered from the students are presented in this section.

In Table 1, it is seen that students' estimates at group A averaged $\bar{x}=5.4$ in normal condition with leader, while leader averages 2.0 .In critical condition students' estimates averaged $\bar{x}=8.1$ in, while leader averages 8 . Students' estimates at group B averaged $\bar{x}=9.1$ in normal condition with leader while leader averages 15.0 and in critical condition students' estimates averaged $\bar{x}=7.4$ in while leader averages 7.0. Students' estimates at group C averaged $\bar{x}=9.4$ in normal condition with leader while leader averages 8.0 and in critical condition students' estimates averaged $\bar{x}=6.2$ in while leader averages 6.5 . Students' estimates at group D averaged $\bar{x}=10.0$ in normal condition with leader while leader averages 20.0 and in critical condition students' estimates averaged $\bar{x}=3.6$ in while leader averages 3.5.

Table 1. 4th Grade Classroom Teachership Students' Compliance With Leader Behavior In Normal And Critical Conditions.

\begin{tabular}{|c|c|c|c|c|c|}
\hline \multicolumn{2}{|c|}{ Classroom Teachership 4th Grade } & \multicolumn{2}{|c|}{ Stone/ kg (8 kg) } & \multicolumn{2}{|c|}{ Cord/m (5m) } \\
\hline & Students & N. C. w/o Leader & N.C. w/Leader & C. C. w/o Leader & $\begin{array}{l}\text { C.C. } w / \\
\text { Leader }\end{array}$ \\
\hline \multirow{6}{*}{ Group A } & A1 (Leader) & 2.0 & 2.0 & 4.0 & 8.0 \\
\hline & A2 & 4.0 & 2.0 & 10.0 & 8.0 \\
\hline & $\mathrm{A} 3$ & 25.0 & 10.0 & 5.0 & 8.0 \\
\hline & A4 & 15.0 & 3.0 & 4.0 & 9.0 \\
\hline & A5 & 15.0 & 10.0 & 5.0 & 7.5 \\
\hline & Group average & 12.2 & 5.4 & 5.6 & 8.1 \\
\hline \multirow{6}{*}{ Group B } & B1 (Leader) & 6.0 & 15.0 & 6.0 & 7.0 \\
\hline & B2 & 25.0 & 10.0 & 6.0 & 7.5 \\
\hline & B3 & 15.0 & 7.5 & 6.0 & 8.0 \\
\hline & B4 & 120.0 & 8.0 & 6.0 & 6.5 \\
\hline & B5 & 5.0 & 5.0 & 20.0 & 7.8 \\
\hline & Group average & 34.2 & 9.1 & 8.8 & 7.4 \\
\hline \multirow{6}{*}{ Group C } & C1(Leader) & 8.0 & 8.0 & 5.5 & 6.5 \\
\hline & $\mathrm{C} 2$ & 5.0 & 5.0 & 4.0 & 5.0 \\
\hline & $\mathrm{C} 3$ & 2.0 & 4.0 & 5.0 & 6.6 \\
\hline & $\mathrm{C} 4$ & 40.0 & 15.0 & 4.5 & 7.0 \\
\hline & $\mathrm{C} 5$ & 8.0 & 15.0 & 4.0 & 6.0 \\
\hline & Group average & 12.6 & 9.4 & 4.6 & 6.2 \\
\hline \multirow{6}{*}{ Group D } & D1 (Leader) & 20.0 & 20.0 & 3.5 & 3.5 \\
\hline & D2 & 14.0 & 14.0 & 4.0 & 4.0 \\
\hline & D3 & 3.0 & 3.0 & 5.0 & 3.0 \\
\hline & D4 & 35.0 & 6.0 & 4.0 & 3.5 \\
\hline & D5 & 10.0 & 7.0 & 5.0 & 4.0 \\
\hline & Group average & 16.4 & 10.0 & 4.3 & 3,6 \\
\hline
\end{tabular}

Table 2. 4th Grade Classroom Teacher Students' Conformity to Leader Levels Group Averages

\begin{tabular}{|c|c|c|}
\hline \multirow{2}{*}{ GROUPS } & \multicolumn{2}{|c|}{ University Students } \\
\cline { 2 - 3 } & Normal Condition & 0,81 \\
\hline Group A & 0,67 & 0,80 \\
\hline Group B & 0,79 & 0,42 \\
\hline Group C & 0,49 & 0,63 \\
\hline Group D & $-0,04$ & 0,67 \\
\hline Conformity to Leader Level Group Averages & 0,48 & \\
\hline
\end{tabular}


Differences between participant and leader estimates in with leader and without leader conditions were calculated. Group A showed $67 \%$ conformity to leader in the normal condition and $81 \%$ in the critical condition. Group B showed $79 \%$ conformity to leader in the normal condition and $80 \%$ in the critical condition. Group C showed $46 \%$ conformity to leader in the normal condition and $42 \%$ in the critical condition, and Group D showed 4\% opposition to leader in the normal condition and $63 \%$ conformity to leader in the critical condition. Averages for all four groups indicate $48 \%$ conformity to leader in the normal condition and $67 \%$ in the critical condition.

In Table 3, it is seen that students' estimates at group A averaged $\bar{x}=3.2$ in normal condition with leader while leader averages 8.1. In critical condition students' estimates averaged $\bar{x}=4.5$ in while leader averages 4.5 . Students' estimates at group B averaged $\bar{x}=6.2$ in normal condition with leader while leader averages 8.1 and in critical condition students' estimates averaged $\bar{x}=3.8$ in while leader averages 3.3. Students' estimates at group C averaged $\bar{x}=4.8$ in normal condition with leader while leader averages 2.2. In critical condition students' estimates averaged $\bar{x}=4.3$ in while leader averages 4.3 . Students' estimates at group D averaged $\bar{x}=6.2$ in normal condition with leader while leader averages 6.8 and in critical condition students' estimates averaged $\bar{x}=4.0$ in while leader averages 3.8.

Table 3. 10th Grade High School Students' Compliance With Leader Behavior In Normal And Critical Conditions.

\begin{tabular}{|c|c|c|c|c|c|}
\hline \multicolumn{2}{|c|}{ High School 10th grade } & \multicolumn{2}{|c|}{ Stone/ kg (8 kg) } & \multicolumn{2}{|c|}{ Cord/m (5m) } \\
\hline & Students & N. C. w/o Leader & N.C. w/ Leader & C. C. w/o Leader & C.C. w/ Leader \\
\hline \multirow{6}{*}{ Group A } & A1 (Leader) & 6,8 & 8,1 & 6,3 & 4,5 \\
\hline & A2 & 0,8 & 2,7 & 0,8 & 4,5 \\
\hline & A3 & 1,6 & 2,2 & 5,0 & 4,5 \\
\hline & A4 & 1,8 & 1,8 & 3,8 & 4,5 \\
\hline & A5 & 14,9 & 1,4 & 1,8 & 4,5 \\
\hline & Group average & 5,2 & 3,2 & 3,5 & 4,5 \\
\hline \multirow{6}{*}{ Group B } & B1 (Leader) & 8,1 & 8,1 & 1,3 & 3,3 \\
\hline & B2 & 2,7 & 13,5 & 2,5 & 3,8 \\
\hline & B3 & 2,0 & 2,7 & 3,8 & 3,8 \\
\hline & $\mathrm{B} 4$ & 5,4 & 5,4 & 1,3 & 3,0 \\
\hline & B5 & 0,7 & 1,4 & 5,0 & 5,0 \\
\hline & Group average & 3,8 & 6,2 & 2,8 & 3,8 \\
\hline \multirow{6}{*}{ Group C } & $\mathrm{C} 1$ (Leader) & 5,4 & 2,2 & 2,0 & 4,3 \\
\hline & $\mathrm{C} 2$ & 1,9 & 2,0 & 3,8 & 4,3 \\
\hline & $\mathrm{C} 3$ & 8,1 & 13,5 & 10,0 & 4,3 \\
\hline & $\mathrm{C} 4$ & 13,5 & 2,2 & 4,3 & 4,3 \\
\hline & $\mathrm{C} 5$ & 4,1 & 4,1 & 2,5 & 4,3 \\
\hline & Group average & 6,6 & 4,8 & 4,5 & 4,3 \\
\hline \multirow{6}{*}{ Group D } & D1 (Leader) & 4,1 & 6,8 & 3,8 & 3,8 \\
\hline & D2 & 6,8 & 6,8 & 12,5 & 3,8 \\
\hline & D3 & 5,4 & 6,8 & 3,0 & 3,8 \\
\hline & D4 & 10,8 & 8,1 & 3,8 & 5,0 \\
\hline & D5 & 0,7 & 2,7 & 2,3 & 3,8 \\
\hline & Group average & 5,5 & 6,2 & 5,1 & 4,0 \\
\hline
\end{tabular}

Table 4. High School 10th Grade Students' Conformity to Leader Level Group Averages

\begin{tabular}{|c|c|c|}
\hline \multirow{2}{*}{ GROUPS } & \multicolumn{2}{|c|}{ High School Students } \\
\cline { 2 - 3 } & Normal Condition & Critical Condition \\
\hline Group A & 0,00 & 1,00 \\
\hline Group B & 0,06 & 0,59 \\
\hline Group C & 0,14 & 1,00 \\
\hline Group D & 0,61 & 0,89 \\
\hline Conformity to Leader Level Group Averages & 0,20 & 0,87 \\
\hline
\end{tabular}


Differences between participant and leader estimates in with leader and without leader conditions were calculated. Group A showed $0 \%$ conformity to leader in the normal condition and $100 \%$ in the critical condition. Group B showed $6 \%$ conformity to leader in the normal condition and $59 \%$ in the critical condition. Group C showed $14 \%$ conformity to leader in the normal condition and $100 \%$ in the critical condition. Group D showed $61 \%$ opposition to leader in the normal condition and $89 \%$ conformity to leader in the critical condition. Averages for all four groups indicate $20 \%$ conformity to leader in the normal condition and $87 \%$ in the critical condition.

In Table 5 , it is seen that students' estimates at group A averaged $\bar{x}=11.6$ in normal condition with leader while leader averages 5.4 and in critical condition students' estimates averaged $\bar{x}=4.36$ in while leader averages 3.8. Students' estimates at group B averaged $\bar{x}=5.3$ in normal condition with leader while leader averages 4.1 and in critical condition students' estimates averaged $\bar{x}=3.52$ in while leader averages 3.8. Students' estimates at group C averaged $\bar{x}=15.7$ in normal condition with leader while leader averages 6.8 and in critical condition students' estimates averaged $\bar{x}=5.1$ in while leader averages 5.0. Students' estimates at group D averaged $\bar{x}=10.62$ in normal condition with leader while leader averages 5.4 and in critical condition students' estimates averaged $\bar{x}=5.02$ in while leader averages 5.0.

In the normal condition, estimate averages of students in all school levels (middle school, high school and higher education) during the estimation phase without leader have shifted in favor of the leader during the estimation phase with leader.

However, the shift was small, and in the normal condition differences of averages between phases with leader and phases without leader are big, they get closer in the critical condition.

Table 5. 7th Grade Middle School Students' Compliance with Leader Behavior in Normal and Critical Conditions

\begin{tabular}{|c|c|c|c|c|c|}
\hline \multicolumn{2}{|c|}{ Middle School 7th Grade } & \multicolumn{2}{|c|}{$\begin{array}{c}\text { Stone/ kg } \\
(8 \mathrm{~kg})\end{array}$} & \multicolumn{2}{|c|}{$\begin{array}{c}\text { Cord } / \mathbf{m} \\
(5 m)\end{array}$} \\
\hline & Students & N. C. w/o Leader & N.C. w/ Leader & C. C. w/o Leader & $\begin{array}{l}\text { C.C. w/ } \\
\text { Leader }\end{array}$ \\
\hline \multirow{6}{*}{ Group A } & A1 (Leader) & 5,4 & 5,4 & 2,5 & 3,8 \\
\hline & $\mathrm{A} 2$ & 4,1 & 4,1 & 2,5 & 3,8 \\
\hline & $\mathrm{A} 3$ & 5,4 & 5,4 & 4,4 & 5,0 \\
\hline & A4 & 3,0 & 35,4 & 6,3 & 5,0 \\
\hline & A5 & 6,5 & 5,5 & 5,4 & 4,2 \\
\hline & Group average & 4,8 & 11,16 & 4,22 & 4,36 \\
\hline \multirow{6}{*}{ Group B } & B1 (Leader) & 2,7 & 4,1 & 3,8 & 3,8 \\
\hline & $\mathrm{B} 2$ & 6,8 & 6,8 & 3,8 & 3,4 \\
\hline & B3 & 8,1 & 5,4 & 2,5 & 3,2 \\
\hline & B4 & 2,7 & 4,6 & 2,5 & 3,8 \\
\hline & B5 & 4,5 & 5,6 & 3,5 & 3,4 \\
\hline & Group average & 4,36 & 5,3 & 3,22 & 3,52 \\
\hline \multirow{6}{*}{ Group C } & C1 (Leader) & 8,1 & 6,8 & 3,8 & 5,0 \\
\hline & $\mathrm{C} 2$ & 6,8 & 20,3 & 7,5 & 5,0 \\
\hline & $\mathrm{C} 3$ & 21,6 & 21,6 & 3,8 & 6,3 \\
\hline & $\mathrm{C} 4$ & 13,5 & 13,5 & 4,3 & 3,0 \\
\hline & $\mathrm{C} 5$ & 2,7 & 16,2 & 5,0 & 6,3 \\
\hline & Group average & 10,5 & 15,7 & 4,9 & 5,1 \\
\hline \multirow{6}{*}{ Group D } & D1 (Leader) & 2,7 & 5,4 & 3,8 & 5,0 \\
\hline & D2 & 16,2 & 16,2 & 0,9 & 5,0 \\
\hline & D3 & 2,2 & 4,1 & 10,0 & 4,8 \\
\hline & D4 & 18,9 & 18,9 & 4,5 & 5,0 \\
\hline & D5 & 15 & 8,5 & 5,4 & 5,3 \\
\hline & Group average & 11 & 10,62 & 4,92 & 5,02 \\
\hline
\end{tabular}


Table 6. Middle School 7th Grade Students' Conformity to Leader Level Group Averages

\begin{tabular}{|c|c|c|}
\hline \multirow{2}{*}{ GROUPS } & \multicolumn{2}{|c|}{ Middle School Students } \\
\cline { 2 - 3 } & Normal Condition & Critical Condition \\
\hline Group A & $-5,34$ & 0,67 \\
\hline Group B & 0,46 & 0,51 \\
\hline Group C & $-0,73$ & 0,14 \\
\hline Group D & 0,32 & 0,95 \\
\hline Conformity to Leader Level Group Averages & $-1,32$ & 0,57 \\
\hline
\end{tabular}

Table 7. 4th Grade Primary School Students' Compliance with Leader Behavior in Normal and Critical Conditions

\begin{tabular}{|c|c|c|c|c|c|}
\hline \multicolumn{2}{|c|}{ Primary School 4th Grade } & \multicolumn{2}{|c|}{ Stone/ kg (8 kg) } & \multicolumn{2}{|c|}{ Cord/m (5m) } \\
\hline & Students & N. C. w/o Leader & N.C. w/ Leader & C. C. w/o Leader & $\begin{array}{l}\text { C.C. w/ } \\
\text { Leader }\end{array}$ \\
\hline \multirow{6}{*}{ Group A } & A1 (Leader) & 16,2 & 16,2 & 0,8 & 2,5 \\
\hline & $\mathrm{A} 2$ & 35 & 18,9 & 0,1 & 2,4 \\
\hline & $\mathrm{A} 3$ & 5,4 & 13,5 & 0,3 & 2,5 \\
\hline & A4 & 0,8 & 21,6 & 0,3 & 2,5 \\
\hline & A5 & 9,5 & 15 & 1 & 2,2 \\
\hline & Group average & 13,38 & 17,04 & 0,5 & 2,42 \\
\hline \multirow{6}{*}{ Group B } & B1 (Leader) & 2,7 & 4,1 & 5,0 & 2,5 \\
\hline & $\mathrm{B} 2$ & 2,7 & 2,7 & 3,8 & 2,5 \\
\hline & B3 & 6,8 & 6,8 & 2,5 & 2,3 \\
\hline & B4 & 2,7 & 2,7 & 5,0 & 2,5 \\
\hline & B5 & 4,5 & 5,5 & 4,2 & 2,7 \\
\hline & Group average & 2,42 & 3,36 & 4,1 & 2,5 \\
\hline \multirow{6}{*}{ Group C } & C1 (Leader) & 0,9 & 0,6 & 2,5 & 3,0 \\
\hline & $\mathrm{C} 2$ & 2,4 & 0,8 & 3,2 & 3,2 \\
\hline & $\mathrm{C} 3$ & 0,1 & 0,4 & 0,5 & 3,0 \\
\hline & $\mathrm{C} 4$ & 5,4 & 0,5 & 5,0 & 3,4 \\
\hline & $\mathrm{C} 5$ & 4,2 & 0,7 & 4,2 & 3,3 \\
\hline & Group average & 2,6 & 0,6 & 3,08 & 3,18 \\
\hline \multirow{6}{*}{ Group D } & D1 (Leader) & 4,1 & 2,4 & 2,5 & 2,5 \\
\hline & D2 & 16,0 & 1,4 & 0,8 & 2,4 \\
\hline & D3 & 2,6 & 2,7 & 0,5 & 2,5 \\
\hline & D4 & 35,0 & 2,7 & 1,6 & 2,5 \\
\hline & D5 & 15 & 2,3 & 1,5 & 2,2 \\
\hline & Group average & 14,54 & 2,3 & 1,38 & 2,42 \\
\hline
\end{tabular}

Differences between participant and leader estimates in with leader and without leader conditions were calculated. Group A showed 534\% opposition to leader in the normal condition and $67 \%$ conformity to leader in the critical condition. Group B showed $46 \%$ conformity to leader in the normal condition and $51 \%$ in the critical condition Group C showed $73 \%$ opposition to leader in the normal condition and $14 \%$ conformity to leader in the critical condition, and Group D showed 32\% conformity to leader in the normal condition and 95\% in the critical condition. Averages for all four groups indicate $132 \%$ opposition to leader in the normal condition and $57 \%$ conformity to leader in the critical condition.
In Table 7, it is seen that students' estimates at group A averaged $\bar{x}=17.04$ in normal condition with leader while leader averages 16.2 and in critical condition students' estimates averaged $\bar{x}=2.42$ in while leader averages 2.5 . Students' estimates at group B averaged $\bar{x}=3.36$ in normal condition with leader while leader averages 4.1 and in critical condition students' estimates averaged $\bar{x}=2.5$ in while leader averages 2.5. Students' estimates at group $\mathrm{C}$ averaged $\bar{x}=0.6$ in normal condition with leader while leader averages 0.6 and in critical condition students' estimates averaged $\bar{x}=3.18$ in while leader averages 3.0. Students' estimates at group D averaged $\bar{x}=2.3$ in normal 
condition with leader while leader averages 2.4 and in critical condition students' estimates averaged $\bar{x}=2.42$ in while leader averages 2.5 .

In the normal condition, estimate averages of students during the estimation phase without leader have shifted in favor of the leader during the estimation phase with leader. In the normal condition differences of averages between phases with leader and phases without leader are big while they are significant in the critical condition.

Table 8. Primary School 4th Grade Students' Conformity to Leader Level Group Averages

\begin{tabular}{|c|c|c|}
\hline \multirow{2}{*}{ GROUPS } & \multicolumn{2}{|c|}{ Primary School Students } \\
\cline { 2 - 3 } & $\begin{array}{c}\text { Normal } \\
\text { Condition }\end{array}$ & $\begin{array}{c}\text { Critical } \\
\text { Condition }\end{array}$ \\
\hline Group A & 0,76 & 0,78 \\
\hline Group B & $-0,16$ & 0,91 \\
\hline Group C & 0,94 & 0,87 \\
\hline Group D & 0,96 & 0,92 \\
\hline $\begin{array}{c}\text { Conformity to Leader Level } \\
\text { Group Averages }\end{array}$ & 0,62 & 0,87 \\
\hline
\end{tabular}

Differences between participant and leader estimates in with leader and without leader conditions were calculated. Group A showed $76 \%$ conformity to leader in the normal condition and $78 \%$ in the critical condition. Group B showed $16 \%$ opposition to leader in the normal condition and $91 \%$ conformity to leader in the critical condition. Group C showed 94\% conformity to leader in the normal condition and $87 \%$ in the critical condition. Group D showed $96 \%$ conformity to leader in the normal condition and $92 \%$ in the critical condition. Averages for all four groups indicate $62 \%$ conformity to leader in the normal condition and $87 \%$ in the critical condition.

As a result, students from all school levels showed higher conformity to leader behaviors in the critical condition.

Table 9. General Averages of Conformity to Leader Levels of All Students

\begin{tabular}{|c|c|}
\hline GROUPS & $\begin{array}{c}\text { General Averages of Conformity to Leader } \\
\text { Levels }\end{array}$ \\
\hline Normal Condition & 0,00 \\
\hline Critical Condition & 0,75 \\
\hline
\end{tabular}

In general, students showed no conformity to leader in normal conditions, but they showed high conformity to leader behavior in critical conditions.

However, because the Group A showed extreme values, new values were calculated excluding these extreme values as shown below.
Table 10. General Averages of Conformity to Leader Levels of All Students (Without Extreme Values)

\begin{tabular}{|c|c|}
\hline GROUPS & $\begin{array}{c}\text { General Averages of Conformity to Leader } \\
\text { Levels }\end{array}$ \\
\hline Normal Condition & 0,33 \\
\hline Critical Condition & 0,74 \\
\hline
\end{tabular}

In this situation, students showed $33 \%$ conformity to leader in normal conditions, and they showed $74 \%$ conformity to leader behavior in critical conditions.

As a result, data of this study indicate that participants showed higher conformity to leader behaviors in the critical condition.

A simple analysis of variance to analyze the mean variability of conformity of groups responding to a leader indicated statistically significant differences in critical situations $(\mathrm{F}(30,49)=2.31, \mathrm{p}<.05)$.

Table 11. The Mean Variability of Conformity of Groups Responding to a Leader in Normal and Critical Situations

\begin{tabular}{|c|c|c|c|c|c|c|}
\hline \multirow{2}{*}{ Situations } & & $d f$ & $\begin{array}{c}\text { Sum of } \\
\text { Squares }\end{array}$ & $\begin{array}{c}\text { Mean } \\
\text { Square }\end{array}$ & $F$ & $p$ \\
\hline \multirow{3}{*}{ Normal } & $\begin{array}{c}\text { Between } \\
\text { Groups }\end{array}$ & 39 & 1891.68 & 48.50 & \multirow{2}{*}{1.32} & .190 \\
\cline { 2 - 6 } & $\begin{array}{c}\text { Within } \\
\text { Groups }\end{array}$ & 40 & 1465.52 & 36.63 & \\
\hline \multirow{2}{*}{ Critical } & $\begin{array}{c}\text { Between } \\
\text { Groups }\end{array}$ & 30 & 132.77 & 4.42 & \multirow{2}{*}{2.31} & \multirow{2}{*}{$.004^{*}$} \\
\cline { 2 - 6 } & $\begin{array}{c}\text { Within } \\
\text { Groups }\end{array}$ & 49 & 93.78 & 1.91 & & \\
\hline
\end{tabular}

$* \mathrm{p}<.05$

One-way analysis of variance test to determine school type differences indicated significant statistically differences in all situations. LSD post hoc test to determine the resource of differences indicated that mean score of university students not responding to a leader in the normal situation is higher than those of the other students. Mean score of middle school students responding to a leader in the normal situation is higher than those of high school and primary school students. Mean score of university students not responding to a leader in the critical situation is higher than those of high school and primary school students. Mean score of primary school students not responding to a leader in the critical situation is lower than those of middle school and high school students. Mean score of university students responding to a leader in the critical situation is higher than those of the other students. Mean score of primary school students responding to a leader in the critical situation is lower than those of middle school and high school students. 
Table 12. The Mean Variability of Students in Normal and Critical Situations

\begin{tabular}{|c|c|c|c|c|c|c|c|}
\hline Situations & Students & $n$ & $\overline{\boldsymbol{X}}$ & $S D$ & $F$ & $p$ & $L S D$ \\
\hline \multirow{4}{*}{ N. C. w/o Leader } & University & 20 & 18.85 & 26.14 & \multirow{4}{*}{3.39} & \multirow{4}{*}{$.022 *$} & \multirow{4}{*}{$\begin{array}{l}1-2 \\
1-3 \\
1-4\end{array}$} \\
\hline & High School & 20 & 5.28 & 4.17 & & & \\
\hline & Middle School & 20 & 7.84 & 5.92 & & & \\
\hline & Primary School & 20 & 8.60 & 10.25 & & & \\
\hline \multirow{4}{*}{ N.C. w/ Leader } & University & 20 & 8.47 & 5.10 & \multirow{4}{*}{3.18} & \multirow{4}{*}{$.028 *$} & \multirow{4}{*}{$\begin{array}{l}2-3 \\
3-4\end{array}$} \\
\hline & High School & 20 & 5.12 & 3.75 & & & \\
\hline & Middle School & 20 & 10.69 & 8.35 & & & \\
\hline & Primary School & 20 & 6.07 & 6.85 & & & \\
\hline \multirow{4}{*}{ C. C. w/o Leader } & University & 20 & 5.82 & 3.62 & \multirow{4}{*}{5.98} & \multirow{4}{*}{$.001 * *$} & \multirow{4}{*}{$\begin{array}{l}1-2 \\
1-4 \\
2-4 \\
3-4\end{array}$} \\
\hline & High School & 20 & 3.98 & 2.88 & & & \\
\hline & Middle School & 20 & 4.31 & 2.00 & & & \\
\hline & Primary School & 20 & 2.26 & 1.76 & & & \\
\hline \multirow{4}{*}{ C.C. w/Leader } & University & 20 & 6.32 & 1.83 & \multirow{4}{*}{39.33} & \multirow{4}{*}{$.000 * *$} & \multirow{4}{*}{$\begin{array}{l}1-2 \\
1-3 \\
1-4 \\
2-4 \\
3-4\end{array}$} \\
\hline & High School & 20 & 4.15 & .51 & & & \\
\hline & Middle School & 20 & 4.50 & .95 & & & \\
\hline & Primary School & 20 & 2.63 & .35 & & & \\
\hline
\end{tabular}

${ }^{*} \mathrm{p}<.05,{ }^{* *} \mathrm{p}<.001,1$ : University, 2: High School, 3: Middle School, 4: Primary School

\section{Results and Discussion}

Results gained in this study from the context of normal situation reveal that primary school students showed higher conformity to leader in normal situation than high school and university students. Children in this age saw conforming to rules of the group they belong to as an obligation [43] and in order not to harm the group; they stated opinions in favour of leaders. In contrast, middle school, high school and university students did not display much conformity to leader in normal situation. Especially middle school students move away from the leader more than other students. The basis of leader - follower relationship, in general, is based on the achievement of a common goal. In normal situation, as the common goal hasn't been constituted yet, it has been behaved generally free and conformity to the leader hasn't been needed. In this sense, the leader's leadership behaviour hasn't occurred by reason of the fact that $s /$ he hasn't inclined to satisfy the needs of followers. In this case, leader tends to satisfy lower need of leadership. Whether leadership is needed or not emerges when human efforts need to be combined and coordinated. Here, the need for leadership is low and the intervention of the leader is considered undesirable [21]. This situation also emphasizes that the followers shouldn't be seen as passive entities [26]. Besides, when it is thought that leader is a person who reduces uncertainties about compulsive expectations [16], a compulsive expectation didn't occur among students in normal situation, thus students did not display conformity behaviour to the leader. In other words, a suitable environment for leader to show leadership behaviour didn't occur. If it is a kind of environment that is insecure or the person can't show the necessary competencies, and the individual wants leader to help. Conversely, when the individual relies on his/her skills, $\mathrm{s} /$ he doesn't want to be interfered by the leader [21].

If individuals who are uncertain about an issue, and believe they can resolve it with their own efforts, the possibility of leaders' intervention to create a positive impact on individual will be very slight and leader's role will decrease [21]. Reducing of the leader's role increases the learning capacity of the organisation [27]. Individuals don't usually show conformity to leader when there isn't a common goal to be accomplished, when they have confidence in their knowledge and skills, or when they are free spirit and tend to behave individually. Here, it's possible to say that the leader's effect on the group varies according to the situation. Circumstances either increase the impact of the leader or limit. Thus, leader will serve in an appropriate time and condition when needed.

Approached from the context of critical situation, results show that primary school, middle school, high school and university students displayed higher conformity behaviour to leader in the critical situation. The critical situation created here directed students to accomplish a common goal. (Offering the group with hypercorrect guess a tour to Georgia-Tbilisi) Moreover, whether there is a need for leadership or not is a situation that emerges when human efforts are needed to be combined and coordinated [25]. Therefore, in critical condition, it was needed to display more conformity to the leader to reach the goal and to minimize aim deviations stemming from different causes. Hains, Hogg, and Duck (1997) emphasized that high level of conformity means that leader approved more [44]. If it is a kind of environment that is insecure and the person can't show the necessary competencies, the individual wants 
leader to help. That is if competency of a person is insufficient for a task, $\mathrm{s} /$ he needs leader more [21]. Also, in societies with a low tolerance for ambiguity, there is more commitment to the decisions of the authority and the belief that the authorities know everything is much [25]. Here when avoidance from uncertainty increases, the desire to be approved also increases [45]. In other words, uncertainty avoidance individuals increases, their need for leadership and leadership will increase the impact on individuals. In other words, as individuals' tendency of avoidance from uncertainty increases, their need for leadership and the impact of leadership on the individual will also increase. In this sense, leaders haven't occurred on their own, social needs have created leaders [23]. Individuals' assumption that leaders are more knowledgeable and experienced than themselves lies behind this. This has led individuals to behave more willingly on listening and accepting instructions and recommendations of leaders having more knowledge and experience [24]. According to people who infer leaders more knowledgeable and experienced than themselves, leaders have qualifications of directing and coordinating [46], and this perception affects individuals easily [47].

The fact that the need for leadership is high means that need for autonomy (making independent decisions) is low. Individual's desire to be guided by someone means that $\mathrm{s} / \mathrm{he}$ abandons his/her right to decide about doing. As need for autonomy is a term closely associated with cultural values $[28,29,30]$, the need for leadership may also be varied according to cultural values. In other words, as leadership is socially constructed, it is inevitable to see the effects of the social and cultural environment in leadership [31]. The effect of cultural values on individuals' need motive is highlighted by researchers $[48,37,29,25,36,49]$. Culture is influential on both leadership behaviour and perception of followers of leadership behaviour [50]. Besides, Hofstede (1980a) emphasises that cultural values affect the individuals' attitudes towards authority and their conformity behaviour [30]. To what extent the individual and community want their tendency to be coordinated by someone else means that they give up their autonomy to the same degree.

Having collectivistic and individualistic behaviours in individual's cultures also affects the attitudes towards leader and their conformity behaviour. While their own choice and autonomy are important for individualists, for collectivists the choices made for them by friends or people they consider authorities are more important [29, 39]. Because the need for others judgment is more significant and the need for autonomy is lower in followers group whose collectivistic values are higher [29, 36], the need for a leader will be more. The need for self-fulfilment, autonomy and the need for self-management of a follower group that is dominated by individualistic values or a person who has individualistic values are higher [29, 36, 39, 40]. According to Sargut (2001), Turkish culture embraces collectivism rather than individualism [25]. While an individual with individualistic values connects to the group with loose ties, in collectivistic values, the individual sees him/herself tied to the group [36]. While making independent decisions are important for individualistic values, it is important to conform to decisions of group or people seen as authorities for collectivistic values [48, 29, 39].

Individuals showing high levels of conformity to leader choose not to take responsibility for solution of a problem, have the mentality to leave it to the leaders, and they just see themselves responsible for fulfilling the tasks assigned. Compatible groups feature homogeneous structure and it also refers to monogolism. Therefore, when this structure is incapable of seeing the mistakes, it negatively affects the group's future. In contrast, independent and critical thinking followers are followers who are willing to make changes and be creative and innovative in organizations [26].

For students who were not given enough opportunity to work independently or if they never had the chance to participate in decisions concerning themselves, it is also difficult to decide on a subject by relying on self-efficacy. Because, mothers fathers adults or teachers undertake the task of decision-making for students from a younger age. Hence, the students internalise being dependent on a redirector and therefore, they tend to conform to leader.

Difference between primary, middle school, high school and university students' level of conformity to leader in normal and critical situation: While middle school, high school and university students didn't display much conformity behaviour to leader in normal situation, primary school students displayed higher conformity behaviour to leader. Primary school, middle school, high school and university students showed high conformity to leader in the critical condition. Middle school students showed lower conformity to leader in the critical condition than other school level students.

\section{Recommendations}

Individuals should be given opportunity to make decisions relying on their own knowledge, skills and experience from a young age. Common goals should be established when directing people somewhere, to some task or when forming an alliance. Moreover, these studies should be done with larger groups of students and their levels of conformity to leader in normal and critical situations should be observed.

\section{REFERENCES}

[1] Başaran, İ. E. (1992). Human Relations in Administration. Ankara: Kadığlu Press.

[2] Bursalığlu, Z. (1987). New structure and behaviour in school management. Ankara: Ankara University Press. 
[3] Aydin, M. (1994). Educational Administration. Ankara: Hatiboğlu Publishing.

[4] Strang, K. D. (2003). Achieving organizational learning across projects. In Paper Presented at the PMI North America Global Congress, Baltimore, MD, USA.

[5] Strang, D. K. (2007). Examining Effective Technology Project Leadership Traits and Behaviours, Computers in Human Behaviours, 23 (1), 424-462.

[6] Robinson, V. M. J., Lloyd, C.A. and Rowe, K. J. (2008). The impact of leadership on student

[7] Outcomes: an analysis of the differential effects of leadership types. Educational Administration Quarterly 44 (5), 635-674.

[8] Owen, H., Hodgson V. and Gazzard, N. (2007). The leadership manual (Liderlik Elkitabı), (Translator: Münevver Çelik) İstanbul: Optimist Yayım Dağıtım.

[9] Johnston, W.S. (2003). Faculty governance and effective academic administrative leadership, new directions for higher education, Wiley Periodicals, 124, 57-63.

[10] Northouse, P. G. (2001). Leadership theory and practice, second edition. Thousand Oaks, CA: Sage Publications, Inc.

[11] Hughes, R., Ginnett, R. and Curphy, G (1999). Leadership, McGraw Hill, NewYork, 1999.

[12] Kreitner, R. and Kinicki, A. (1998). Organisational behaviour. Boston: McGraw-Hill.

[13] Davis, S. F. and Palladino, J. J. (1997). Psychology. New Jersey: Prentice Hall, Upper Saddle River.

[14] Groome, D., Dewart, H., Esgate, A., Gurney, K., Kemp, R. and Towell, N. (2001). An introduction to cognitive psychology: Processes and disorders. East Sussex: Psychology Press.

[15] Gordon, J. R. (1996). Organisational behaviour: A diagnostic approach. New Jersey: Prentice Hall International.

[16] Caruso, D., Mayer, J.D. \& Salovey, P. (2002). Emotional intelligence and emotional Leadership. In R. Riggio \& S. Murphy \& F. J. Pirozzolo (Eds.). Multiple Intelligences and Leadership. Mahwah, NJ: Lawrence Erlbaum.

[17] Tosı, H.L., J. R. Rizzo , S. J. and Carrol L. (1990). Managing Organizational Behavior, New York: Second Edition, Harper Collins Publishers.

[18] House, R. J. (1971). A path-goal theory of leader effectiveness. Administrative Science Quarterly, 16, 321339.

[19] House, R, J. (1996). Path-goal theory of leadership: Lessons legacy and a reformulated theory. Leadership Quarterly. 7 (3), 323-352.

[20] Hoy, W. K. and Miskel, C. G. (2010). Educational administration theory, research and application. (translator. editor. S. Turan). Ankara: Nobel Publishing.

[21] Porter, L. W. and Mclaughlın, G. B. (2006). Leadership and the organizational context: Like the weather?, The Leadership Quarterly, 17 (6), 559-576.

[22] De Vries, R.E., Roe, R.A. and Taillieu, T.C.B. (2002). Need for leadership as a moderator of the relationships between leadership and individual outcomes. Leadership Quarterly. 13, 121-137.
[23] Eraslan, L. (2004). Historical evolution of leadership phenomenon, basic concepts and analysis of new leadership paradigms, National Education Journal, Number 162, 26-35.

[24] Fındıkçı, İ. (2009). A journey to heart service leadership, İstanbul: Alfa Publishing.

[25] Dyer, W. (1979). Caring and power, California Management Review, 21 (4), 84-89

[26] Sargut, S. (2001). Kültürler arası farklılaşma ve yönetim. İstanbul: İmge Yayınları.

[27] Kelley, R. (1992). The power of followership. New York: Doubleday.

[28] Evers, C.W. and Lakomsky, G. (2001). Theory in educational administration: Naturalistic directions, Journal of Education, $6(39), 499-520$

[29] Deci, E. L., Ryan, R. M., Gagne, M., Leone, D. R., Usunov, J. and Kornazheva, B. P. (2001). Need satisfaction, motivation, and well-being in the work organizations of a former eastern block country: A cross-cultural study of self-determination. Personality and Social Psychological Bulletin, 27 (8), 930-942.

[30] Triandis, H. and Suh, E.M. (2002). Cultural Influences on Personality. Annual Review of Psychology, 53, 133- 160.

[31] Hofstede, G. (1980 a). Culture's consequences: International differences in work-related values. Newbury Park, CA: Sage. Publications.

[32] Fairhurst, G. and Grant, D. (2010). The social construction of leadership: A sailing guide. Management Communication Quarterly, 24 (2), 171-210.

[33] Hofstede, G. and McCrae, R. R. (2004). Personality and Culture Revisited: Linking Traits and Dimensions of Culture, Cross-Cultural Research, 38 (1), 52-88.

[34] Triandis, H. C. (2000). Culture and Conflict, International Journal of Psychology, 35 (2), 145- 152.

[35] Voronov, M. and Singer, J. A. (2002). "The Myth of Individualism-Collectivism: A Critical Review”, The Journal of Social Psychology, 142 (4), 461-480.

[36] Hogg, M. A. and Vaughan, G. M. (2006). Social Physchology. Translator: İbrahim Yıldız- Aydın Gelmez. 1st edition. Ankara: Ütopya Publishing.

[37] Markus, H. R. and Kitayama, S. (1991) Culture and the self: implications for cognition, emotion, and motivation. Psychological Review, 98 (2), 224-253.

[38] Triandis, H. C. (1995). Individualism and collectivism. Boulder, CO: Westview Press.

[39] Nisbett R. E., Peng K., Choi I. and Norenzayan, A. (2001). Culture and systems of thought: holistic versus analytic cognition. Psychol. Review, 108, 291-310.

[40] Gelfand, M. J., Bhawuk, D. P. S., Nishii, L. H. and Bechtold,D. J. (2004). Individualism and Collectivism. In R. J. House, P. J. Hanges, M. Javidan, P. W. Dorfman, \& V. Gupta (Der.), Culture, leadership, and organizations: The GLOBE study of 62 societies, Vol. 1. Thousand Oaks, CA: Sage. Publications. 
[41] Iyengar, S.S. and Lepper, M. R. (1999). Rethinking the value of choice: a cultural perspective on intrinsic motivation. Journal of Personality and Social Psychology. 76, 349-366.

[42] Karasar, N. (2004). Scientific research method. Ankara: Nobel Publishing.

[43] Büyüköztürk, Ş., Çakmak, E., Akgün, Ö. E., Karadeniz, Ş. and Demirel, F. (2009). Scientific Research Methods (2nd Edition). Ankara: Pegem A Publishing.

[44] Başaran, İ. E. (1991). Educational Physcology. Ankara: Kadıoğlu Press.

[45] Hains, S. C., Hogg, M. A. and Duck, J. M. (1997). Self-categorization and leadership: Effects of group prototypicality and leader stereotypicality. Personality and Social Psychology Bulletin, 23, 1087-1100.
[46] De Luque, S. M. and Javidan M. (2004). "Uncertainty avoidance" House eat all (eds.) Culture, Leadership and Organizations: The GLOBE Study of 62 Societies, Thousand Oaks, Sage Publications.

[47] Mullins, Laurie, J. (1996). Management and organisational behaviour (4th ed.). London: Pitman,

[48] Koçel, T. (2007). Business Management (11. Edition). İstanbul: Arıkan Publishing.

[49] Hofstede, G. (1980 b). Motivation leadership and organization: Do American theories apply abroad? Organizational Dynamics, 42-63.

[50] Schwartz, S. H. (1999). A theory of cultural values and some implications for work. Applied Psychology: An International Review, 48, 23-47.

[51] Shahin, Amany L. and Peter L. Wright (2004), Leadership in the context of culture: An Egyptian perspective, Leadership \& Organization Development Journal, 25 (5/6), 499-511. 